\title{
Giro Cultural: Os Desafios de uma Proposta Inovadora na USP
}

\author{
Giro Cultural: the Challenges of an Innovative Proposal in \\ the University of São Paulo
}

\section{RESUMO}

Neste artigo vamos apresentar a proposta do programa Giro Cultural, relatando todas as etapas de sua criação e implantação. $O$ programa se propõe a difícil tarefa de apresentar à sociedade, de forma regular e contínua, os diferentes patrimônios que estão sob a guarda da Universidade de São Paulo, inclusive aqueles que não estão expostos da maneira tradicional. Assim, criou-se um programa de visitas monitoradas, com diferentes roteiros que permitem ao visitante entrar em contato com a biodiversidade dos campi, as coleções que estão expostas nas unidades ou fazer um percurso pela cidade de São Paulo, conhecendo a história da cidade e as condições da criação e implantação da USP.

Palavras-chave: Divulgação cultural. Patrimônio cultural. Visitas guiadas.

\section{ABSTRACT}

In this article we present the Giro Cultural Program, reporting all stages of its conception, development and implementation. This program proposal is to accomplish the difficult task of presenting and sharing with the general society the rich cultural heritage belonging to the University of São Paulo, including objects, buildings and even gardens that are not opened to visitors in the traditional way. We choose to create a schedule of monitored tours in the city of São Paulo presenting the visitors the history of the city and the conditions of the implementation of the University of São Paulo and, at the same time, allowing them the contact to the biodiversity of the campuses and the collections that are exposed in different colleges of the University.

Keywords (Keywords): Cultural diffusion. Cultural patrimony. Guided tours. 


\section{INTRODUÇÃO E ANTECEDENTES}

\section{O programa Giro Cultural da Pró-Reitoria de Cultura e Extensão Universitária}

da USP é um programa inovador e que apresenta desafios inéditos para a gestão da cultura e da extensão da Universidade.

Como será detalhado a seguir, trata-se de um programa de apresentação à sociedade - entendida no seu sentido maior, não apenas constituída pela comunidade uspiana do patrimônio arquitetônico, cultural, físico, histórico e científico que a Universidade de São Paulo é depositária.

Trata-se, portanto, de um programa que atende às obrigações mais fundamentais da Universidade, de ser um agente de difusão de conhecimento no seio da comunidade em que está inserida.

O programa já constava das ideias iniciais que a pró-reitora de Cultura e Extensão Universitária, Maria Arminda do Nascimento Arruda, apresentava na plataforma de ações propostas para o seu período na direção da área de Cultura e Extensão da USP. Quando de sua posse como pró-reitora, em 2010, ela já expressou o desejo de criar algo que se assemelhasse a um "passaporte" que desse acesso às muitas ações culturais oferecidas pela USP e que nem sempre eram adequadamente divulgadas aos eventuais interessados.

No sítio da Pró-Reitoria de Cultura e Extensão Universitária, lemos no documento Diretrizes de ação da Pró-Reitoria de Cultura e Extensão [1]:

Por esses motivos, o amplo acesso aos fenômenos culturais promove, amplia e garante tanto a inserção social daqueles situados à margem quanto à fixação de princípios de cidadania, dirimindo as desigualdades e reforçando valores republicanos.

$[\ldots]$

A USP ocupa um lugar privilegiado nesse contexto, pois é capaz de oferecer os meios indispensáveis ao ingresso, circulação e difusão da cultura e da ciência, tanto no meio universitário, quanto externamente a ele.

Ao mesmo tempo, a Prefeitura do Campus do Butantã - na época denominada Coordenadoria do Campus - lidava com uma temática candente e plena de desafios. De um lado, a Coordenadoria/Prefeitura possuía poucas informações sobre os usuários do campus e era o local de canalização do descontentamento da sociedade, que questionava o fechamento do campus nos finais de semana. Para a sociedade, o campus era visto como um parque público e, como tal, deveria estar aberto ao uso coletivo. Questões como a sua conservação, sua destinação prioritária para as atividades de ensino e pesquisa e não de lazer passavam ao largo das preocupações do cidadão comum.

Para a primeira questão, a Prefeitura do Campus firmou um convênio com o Instituto de Matemática e Estatística, que apoiou academicamente a realização de pesquisas que contribuíram para introduzir uma nova forma de olhar o campus, como sendo uma espécie de laboratório da Universidade.

Para tratar da segunda questão, a equipe instalada na Prefeitura começou um processo interno de reflexão sobre o uso do campus, que, posteriormente, culminou na 
realização de duas edições do Fórum Permanente sobre o Espaço Público, a USP e a Especificidade de seus Campi. Percebe-se, então, que havia na Prefeitura uma prontidão para abraçar uma causa como a proposta pela recém-empossada pró-reitora.

A necessidade de se aprofundar estas reflexões sobre o uso do campus e sua relação com a sociedade pode ser facilmente compreendida se pensarmos sobre um simples aspecto desta relação. Nesta época, o campus fechava aos domingos para a comunidade externa à USP, sendo que os portadores de crachá de identificação institucional tinham acesso.

Os visitantes que se destinavam aos museus funcionando em seu interior, o de Arte Contemporânea (MAC) e o de Arqueologia e Etnologia (MAE) tinham acesso garantido à Cidade Universitária, mas os ônibus circulares - mantidos pela administração central da USP - faziam uma viagem a cada hora; não havia banheiros públicos externos aos museus, nem lanchonetes, cafés, livrarias ou qualquer outro tipo de facilidade disponível aos visitantes.

\section{PRIMEIROS PASSOS}

Urgia pensar esta questão de forma orgânica, estruturada e - por que não dizer - acadêmica.

Em poucas reuniões e de forma célere, o reitor da USP, João Grandino Rodas, o então coordenador do campus, Antonio de Aguirre Massola, juntamente com a pró- reitora, acordaram na montagem de um projeto que, na falta de um nome oficial, foi tratado internamente e por algum tempo como "Passaporte Cultural".

Em março de 2011, uma portaria da Pró-Reitoria cria um grupo de trabalho encarregado de apresentar propostas ao programa Passaporte Cultural. Este grupo tinha a seguinte composição:

" Professores: Edson Leite (coordenador), Claudio Possani (vice-coordenador), Esmeralda Vailati Negrão, Hussam El Dine Zaher, Lorenzo Mammi e Martin Grossmann.

" Funcionários: Cristina Guarnieri, Cecílio de Souza, Eduardo Alves, Evania Maria Guilhon e Sá, José Clóvis de Medeiros Lima e Regina Carvalho.

Um dos pilares do programa, como de tantos outros da Pró-Reitoria de Cultura e Extensão da USP, foi ter, desde o início, a clareza de que as ações a serem desenvolvidas deveriam necessariamente integrar docentes, funcionários e alunos, bem como deveriam contemplar as três faces do fazer acadêmico, a pesquisa, o ensino e a extensão. Os alunos sempre estiveram presentes como estagiários e têm sido importantes agentes do Giro Cultural.

Neste ponto deste artigo abro um parêntese para elaborar reflexão sobre o fazer acadêmico, ou melhor, sobre qualquer fazer, mesmo administrativo, quando o contexto e as preocupações são acadêmicos.

Nas primeiras reuniões foram exploradas inúmeras e diferentes possibilidades. Planos nem sempre realistas consumiram tempo da equipe presente até que ficasse claro 
que eles não eram exequíveis. Ideias interessantes geravam grande entusiasmo entre os participantes e alongavam as discussões. As primeiras tentativas de ações concretas esbarravam em dificuldades operacionais não previstas. Em alguns momentos, tive a impressão de que talvez estivesse participando de mais um projeto que não produziria resultados práticos.

Quase um ano foi consumido nesta etapa.

Minha visão de hoje é que esta fase tinha que ser vivenciada desta forma. Nestas discussões, o alicerce do projeto e os conceitos básicos foram estruturados.

Lição: nas atividades acadêmicas, não há que ter pressa; há que se evitar o perfeccionismo paralisante, tanto quanto a pressão pelos resultados de curto prazo.

Uma das primeiras ações que se realizou no escopo destas discussões foi um levantamento dos hábitos culturais dos alunos da USP. Para isso, foi utilizada uma base de dados da Pró-Reitoria de Graduação da Universidade, constituída por um questionário respondido de forma voluntária, via web, pelos alunos de graduação, quando de seu primeiro acesso ao sistema de matrículas on-line. O levantamento - em que pese o fato de não se basear em amostra escolhida de maneira estatisticamente rigorosa - apontou que os hábitos culturais dos nossos alunos não diferem de forma significativa daqueles da população em geral. Nossos indicadores são só um pouco melhores do que os apontados por pesquisas realizadas pelo Instituto de Pesquisas Econômicas Aplicadas (Ipea) [2] e pela Federação do Comércio do Rio de Janeiro (FECOMERCIO-RJ).

Dos 7 mil alunos cujas respostas foram analisadas, $74,9 \%$ declararam que "raramente ou nunca" frequentavam eventos ligados às artes visuais. Para eventos de dança, o número é de 80,8\%, mesmo número para apresentações de música erudita. Teatro "raramente ou nunca" é frequentado por $71,7 \%$ dos respondentes. Para eventos de literatura, o índice é $72,2 \%$, e para eventos de música popular, $57,7 \%$. O número dos que declararam que nunca ou raramente frequentam cinema é de $22,1 \%$.

É claro que estes números são significativos e transcendem os limites do projeto do Giro Cultural. Há aí um grande desafio para as futuras administrações da Universidade: aprofundar esta compreensão do perfil cultural do aluno USP e incorporar esta realidade às políticas do setor cultural.

A partir destas reuniões e discussões, começou a se estruturar um formato de ação, as visitas guiadas, mostrando o patrimônio da USP, sendo que os roteiros seriam objeto de explicações e descrições escritas por professores da Universidade.

Este fato básico e fundamental garantiria um diferencial importante: estas visitas guiadas teriam lastro conceitual, diferentemente de muitas visitas guiadas de caráter turístico.

\section{O ROTEIRO DO CAMPUS BUTANTÃ}

Vários roteiros foram analisados e podemos dizer que "aprovados" internamente na comissão, alguns foram implantados e outros estão em fase de "redação".

Um roteiro foi quase imediatamente formatado, o do campus Butantã. Neste roteiro, percorremos o campus mostrando os prédios, a história da Cidade Universitária e como ela foi concebida e implantada. 
Em meados de 2012, houve uma mudança no sistema de transporte interno do campus. As famosas linhas circulares 1 e 2 foram desativadas e a comunidade USP passou a ter acesso gratuito às linhas regulares que circulam na Cidade Universitária. Parte dos ônibus, motoristas e estrutura que serviam às extintas linhas circulares foi colocada a serviço do Giro Cultural. Este momento foi de fundamental importância para que o programa, de fato, se fizesse visível.

\section{AS DELEGAÇÕES ESTRANGEIRAS}

Aqui cabe destacar um fato da maior relevância: a importância deste programa para a área internacional da USP. A educação superior em todo o mundo passa por uma mudança de paradigma, no qual a mobilidade de estudantes de graduação e de pós-graduação assume um protagonismo inédito nas prioridades das instituições. O Brasil, graças ao seu desenvolvimento econômico da primeira década do século XXI, atrai a atenção de muitas universidades do mundo todo. A USP em particular, graças ao seu prestígio, ao trabalho dos seus pesquisadores, à excelência dos seus alunos e ao seu desempenho em rankings internacionais de avaliação de universidades, tornou-se uma parceira em potencial para as principais universidades do mundo. Um número mostra esta realidade: em 2012, a Vice-Reitoria Executiva de Relações Internacionais da USP recebeu mais de trezentas delegações de universidades estrangeiras. Muitas destas delegações são formadas por muitas pessoas (algumas chegam a dezenas de componentes!) e um pedido frequente é o de conhecer o campus. Antes do Giro Cultural não havia estrutura para recepcionar estes visitantes; mas agora, trabalhando em parceria com a Pró-Reitoria de Cultura e Extensão, a área internacional da Universidade pode, finalmente, receber seus visitantes internacionais de forma adequada. A Vice-Reitoria incluiu o Giro nas atividades de recepção aos alunos estrangeiros que chegam ao Brasil para fazerem intercâmbio de estudos.

Como curiosidade, destaco que os visitantes internacionais apreciam muito a Praça do Relógio, sendo comum eles passarem muitos minutos tirando fotos no local.

Vários aspectos surpreendem os visitantes, tanto brasileiros como estrangeiros: a beleza e as dimensões do campus, com suas árvores e flores, o encanto da Torre do Relógio e seus símbolos, a Praça do Relógio como um todo, a existência de um complexo olímpico com velódromo e raia olímpica, a história deste complexo e as esculturas a céu aberto. 
Tabela 1 Número de visitantes atendidos pelo programa Giro Cultural oriundos das atividades de intercâmbio internacional promovidas pela USP, de outubro de 2011 a abril de 2012.

\begin{tabular}{|c|c|c|c|}
\hline MÊS DA VISITA & VISITANTES & DESTINO & $\begin{array}{l}\text { NÚMERO DE } \\
\text { VISITANTES }\end{array}$ \\
\hline Outubro de 2011 & $\begin{array}{l}\text { Alunos e professores } \\
\text { chineses participantes } \\
\text { do Programa } \\
\text { TOP Brasil-UK do } \\
\text { Santander }\end{array}$ & Campus Butantã & 46 \\
\hline Novembro 2012 & $\begin{array}{l}\text { Professores e } \\
\text { administradores da } \\
\text { Universidade de } \\
\text { Assunção, Paraguai }\end{array}$ & Campus Butantã & 15 \\
\hline Março 2012 & $\begin{array}{l}\text { Professores } \\
\text { de diferentes } \\
\text { Universidades da } \\
\text { Coreia }\end{array}$ & Campus Butantã & 10 \\
\hline Março 2012 & $\begin{array}{l}\text { University of Surrey/ } \\
\text { UK e North Carolina } \\
\text { State University/EUA }\end{array}$ & $\begin{array}{l}\text { Campus Butantã e } \\
\text { MAC/lbirapuera }\end{array}$ & 32 \\
\hline Março 2012 & $\begin{array}{l}\text { Professores do } \\
\text { Consórcio WC2 }\end{array}$ & $\begin{array}{l}\text { Campus Butantã e } \\
\text { MAC/Ibirapuera }\end{array}$ & 38 \\
\hline Abril 2012 & $\begin{array}{l}\text { Professores da } \\
\text { reunião do CODOC } \\
\text { - Cooperation on } \\
\text { Doctoral Education } \\
\text { between Africa, Asia, } \\
\text { Latin America and } \\
\text { Europe }\end{array}$ & Campus Butantã & 25 \\
\hline
\end{tabular}

Nestas primeiras visitas, o total de visitantes foi 166, atestando a importância desta parceria para as ações de cooperação internacional da USP.

\section{CALOUROS E FEIRA DAS PROFISSÕES.}

A visita do campus Butantã também está sendo introduzida aos poucos por algumas unidades na programação da Semana de Recepção aos Ingressantes, importante atividade coordenada anualmente pela Pró-Reitoria de Graduação. Em 2012 - o primeiro ano em que ocorreu -, 220 calouros fizeram o tour pelo campus.

$\mathrm{Na}$ edição de 2012 da Feira das Profissões, mais de 460 pessoas fizeram o tour pela Cidade Universitária, também conhecida como CUASO.

Estes dados mostram que a ideia do Giro Cultural está se inserindo no dia a dia da Universidade e vai se tornando parte do seu cotidiano. 


\section{OS ROTEIROS ATUAIS NO BUTANTÃ}

Hoje estão em funcionamento, de forma regular, três roteiros no campus Butantã, cujas descrições seguem [3]:

Vista Panorâmica: um passeio pelo campus

Visita ao campus da Cidade Universitária Armando de Salles Oliveira, na qual os visitantes podem conhecer a história da USP e da criação do campus, além de receber informações sobre cada uma das escolas, faculdades, institutos e museus ali localizados. [...]

\section{Acervo Cultural}

Visita com paradas no Museu de Arte Contemporânea (MAC SP), Paço das Artes, Museu do Brinquedo (Faculdade de Educação) e Instituto de Estudos Brasileiros (IEB). [...]

\section{Científico}

Roteiro com paradas no Museu de Geociências (IGc), Museu Oceanográfico (IO), Show de Física (Instituto de Física), Museu de Anatomia Veterinária (Faculdade de Medicina Veterinária e Zootecnia). [...]

Os passeios contam com ônibus e motorista treinado, cedidos pela Prefeitura do Campus USP da Capital. As partidas e retornos acontecem sempre no Centro de Informações da USP, localizado na Praça Reynaldo Porchat, 110, próximo à Portaria 1 da Universidade.

As primeiras 116 inscrições para estes três roteiros tiveram a seguinte distribuição de interesse (Gráfico 1): 14 para o roteiro geral (Vista Panorâmica) da Cidade Universitária, 58 para o roteiro cultural (Acervo Cultural) e 44 para o roteiro científico (Científico).

Gráfico 1 Número de inscritos nos roteiros de visita ao campus Butantã.

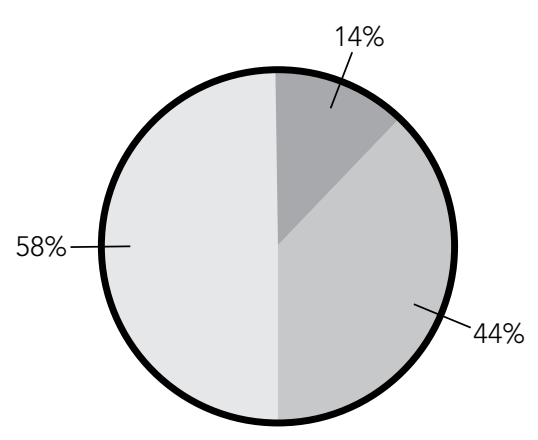

Roteiro Acervo Cultural

$\square$ Roteiro Científico

Roteiro CUASO 


\section{O ROTEIRO DA SÃO PAULO MODERNISTA}

Outro momento fundamental para a implantação do programa foi a contratação de empresa externa à Universidade para realizar a visita chamada de "São Paulo Modernista", cuja concepção básica é do professor Martin Grossmann.

Numa Universidade do porte da USP, muitas vezes temos a impressão de que tudo podemos e tudo sabemos, correndo o risco de tentar assumir funções para as quais não temos estrutura nem condições materiais para sua execução. Para este roteiro, após muita reflexão, a opção foi pela contratação de uma empresa profissional nesta atividade.

Este roteiro começa junto aos edifícios do Museu Paulista e do Museu de Zoologia, com destaque para a arquitetura em si e o fato de que estas edificações tiveram um sentido importante na São Paulo do século XIX. Em seguida, o ônibus leva os visitantes para a região central de São Paulo e aborda-se a modernização da cidade no começo do século XX. A Semana de Arte Moderna e a própria criação da USP são contextualizadas dentro do movimento modernista. O significado arquitetônico, artístico e social de alguns edifícios marcantes da cidade é discutido. Em seguida, os visitantes são levados ao Parque do Ibirapuera, onde podem ver algumas obras de Oscar Niemeyer, e o roteiro terminará com visita ao novo prédio do MAC no Ibirapuera.

Compreensivamente, este roteiro - que será descrito adiante [3] - tem despertado grande interesse da sociedade. A procura é grande e as vagas se esgotam com semanas de antecedência.

\section{A USP e a São Paulo Modernista}

A USP e a São Paulo Modernista é o primeiro roteiro do Giro Cultural USP realizado fora da Cidade Universitária. Com ponto de partida na estação Alto do Ipiranga do Metrô, o passeio tem início no Museu Paulista, no bairro do Ipiranga, passando pelo centro da cidade, onde destaca as principais edificações modernistas, como o Edifício Copan, do arquiteto Oscar Niemeyer. O ponto de parada seguinte é o prédio da Faculdade de Arquitetura e Urbanismo na Rua Maranhão, no bairro de Higienópolis, um casarão art nouveau do início do século XX. O passeio termina no Museu de Arte Contemporânea da USP, no Parque do Ibirapuera.

O roteiro procura oferecer aos visitantes um olhar e uma leitura distintos sobre a implantação do modernismo na cidade, em suas múltiplas dimensões (arquitetônica, urbanística, econômica, sociocultural e política), evidenciando a passagem do século XIX até o ápice da consolidação do projeto modernista na cidade de São Paulo, nos anos 1950.

O roteiro conta com uma equipe de mediadores composta por historiadores, artistas plásticos e arquitetos, além de um guia da Embratur. Todo trajeto é percorrido em um ônibus equipado com recursos multimídia para uso durante o passeio. 


\section{O MOMENTO ATUAL E O FUTURO}

Podemos afirmar com convicção e orgulho que o programa Giro Cultural é uma realidade e faz parte, ainda que de forma incipiente, do cotidiano da Universidade. Os desafios vencidos foram muitos, como relatamos neste artigo.

E os próximos passos? Os desafios futuros são ainda maiores: é necessário atender a demanda pela visita da São Paulo Modernista para não frustrar os interessados; é necessário incorporar os demais campi nesta concepção alternativa de como abrir os acervos, coleções e o patrimônio da USP à sociedade que está ao nosso redor e que nos financia; é necessário criar novos roteiros. As ideias são muitas e podemos citar algumas:

"Visita ao campus Butantã observando a fauna e a flora da Cidade Universitária, uma verdadeira aula de Ecologia;

"Caminhadas pelo campus Butantã com diferentes olhares: as esculturas, a flora, os prédios;

"I Incorporar aos roteiros atuais e futuros as manifestações artísticas de grupos da comunidade universitária: Coral da USP, orquestras, grupos de teatro, baterias, dentre outros.

Outro desafio é o de oferecer visitas em outras línguas. Hoje, há demanda por visitas oferecidas em inglês e espanhol, principalmente naquelas que se originam na área de Relações Internacionais. Ainda não temos uma solução definitiva. As visitas em inglês são feitas quase sempre pelo funcionário da Pró-Reitoria de Cultura e Extensão Vitor Borysow e, às vezes, por algum professor disponível.

Também será importante que o programa mantenha uma base de dados constantemente atualizada sobre o perfil dos seus usuários. Não podemos perder a oportunidade de conhecer melhor o perfil dos interessados, pois esta informação é de suma importância para a definição das melhores políticas de cultura dentro da Universidade.

\section{DIVULGAÇÃO}

Damos a seguir uma lista, obviamente incompleta, de diferentes meios de comunicação que, de alguma forma, repercutiram o Giro Cultural. Sem dúvida, é uma medida da importância e do impacto social do programa, bem como de seu potencial de interação com a sociedade.

\section{UNIVERSIDADE DE SÃO PAULO}

http://www.usp.br/imprensa/wp-content/uploads/veja_sp_180612.jpg http://www.usp.br/imprensa/?p=22039

http://www.usp.br/agen/?p=101419 


\section{UNIVERSIA}

http://agenda.universia.com.br/usp/2012/o6/o8/

giro-cultural-divulga-riqueza-do-patrimonio-da-usp

\section{UNIVESP}

http://www.univesp.ensinosuperior.sp.gov.br/preunivesp/3470/giro-cultural-di-

vulga-riqueza-do-patrim-nio-da-usp.html

\section{DIRIGIDA}

http://www.dirigida.com.br/news/pt_br/giro_cultural_divulga_riqueza_do_ patrimonio_da_usp_salario_minimo/redirect_8856746.html

\section{BLOGS}

http://www.bloglunabianca.com.br/desbravando-a-usp/

http://marthapimenta.blogspot.com.br/2012/o6/giro-cultural-na-usp.html http://cultlove.com.br/2012/o6/19/

usp-promove-tours-tematicos-gratuitos-na-cidade-universitaria/

http://alrocha-antenacultural.blogspot.com.br/2012_06_10_archive.html

http://www.salariominimo.net/2012/06/o6/

giro-cultural-divulga-riqueza-do-patrimonio-da-usp/

http://www.artenaescolauenf.org/website/index.

php?option $=$ com_marketplace $\&$ page $=$ show_ad $\&$ catid $=19 \&$ adid $=912$

\section{REDES SOCIAIS}

http://twitter.com/VejaSP/statuses/214402198686285824

http://twitter.com/caminhosusp/status/214824737023602688

http://pt-br.facebook.com/fousp/posts/235726966543776

http://www.orkut.com/Main\#CommMsgs? $\mathrm{cmm}=35362 \& \mathrm{tid}=57375489198406112$

$63 \& n a=2 \& n s t=101$

\section{IMPRENSA OFICIAL}

http://diariooficial.imprensaoficial.com.br/nav_v4/index. asp $? \mathrm{c}=4 \& \mathrm{e}=20120616 \& \mathrm{p}=1$ (Pg. III)

http://diariooficial.imprensaoficial.com.br/nav_v4/index. asp $? c=4 \& e=20120713 \& p=1(\operatorname{PgIV})$

\section{REFERÊNCIAS BIBLIOGRÁFICAS}

[1] ARRUDA, Maria Arminda do Nascimento. Diretrizes de ação da Pró-Reitoria de Cultura e Extensão. Disponível em: <http://www.prceu.usp.br/diretrizes. php\#.UTNAjKJOT6w>. Acesso em: 28 fev. 2013.

[2] BRASIL. Secretaria de Assuntos Estratégicos da Presidência da República. 
Instituto de Pesquisas Econômicas Aplicadas. Sistema de indicadores de percepção social: Cultura. Brasília, DF, 17 nov.2010. 16 p.

[3] UNIVERSIDADE DE SÃO PAULO. Pró-Reitoria de Cultura e Extensão Universitária. Giro Cultural USP. Disponível em: <http://www.prceu.usp.br/programas/girocultural/visitassp.php $>$. Acesso em: 3 mar. 2013.

\section{AGRADECIMENTOS}

O autor agradece a todos os colaboradores do Projeto Giro Cultural e em especial à pró-reitora de Cultura e Extensão, profa. dra. Maria Arminda do Nascimento Arruda pela oportunidade deste trabalho conjunto. À Regina Carvalho registro meu agradecimento pela ajuda na redação deste artigo.

CLAUDIO POSSANI professor doutor do Departamento de Matemática do Instituto de Matemática e Estatística da Universidade de São Paulo - R. do Matão, 1010 - Cidade Universitária - CEP 05508ogo - SãoPaulo-SP - e-mail: cpossani@ime.usp.br. 